\title{
Managing creative industries in the context of knowledge-based urban development
}

\section{Maria do Rosário Cabrita* and Virgílio Cruz-Machado}

\section{UNIDEMI,}

Department of Mechanical and Industrial Engineering, Faculty of Science and Technology, FCT

Universidade Nova de Lisboa, 2829-516 Caparica, Portugal

E-mail:m.cabrita@fct.unl.pt

E-mail: vcm@fct.unl.pt

*Corresponding author

\section{Cristina Cabrita}

ISCTE-IUL Lisbon University Institute,

Avenida Forças Armadas, 1649-026 Lisbon, Portugal E-mail: cristinacabrita.arq@gmail.com

\begin{abstract}
The advent of the knowledge economy has put the focus on innovation, creativity and networks as drivers of competitiveness and economic growth. This has shifted development perspectives from tangibles-based competitiveness to knowledge-driven competitiveness transforming the way the economy is organised and putting emphasis on the emergence of a new type of capital. Creative industries represent a form of capital that provides economic benefits and the links between creative capital, quality of life and competitiveness has made the creative industries a serious economic factor that needs to be considered in regard to cities and regions viability. The two issues, creative industries and knowledge-based urban development (KBUD) remain not only challenging fields of research but also the key elements for discussions on the competitiveness of cities and regions. The purpose of this paper is to explore the 'creative industry' concept to relate it to the ongoing process of creating knowledge-based urban developments.
\end{abstract}

Keywords: creativity; creative economy; creative industries; knowledge-based development; KBD; knowledge-based urban development; KBUD.

Reference to this paper should be made as follows: Cabrita, M.R., Cruz-Machado, V. and Cabrita, C. (2013) 'Managing creative industries in the context of knowledge-based urban development', Int. J. Knowledge-Based Development, Vol. 4, No. 4, pp.318-337.

Biographical notes: Maria do Rosário Cabrita is a Professor and Researcher at Faculty of Science and Technology (FCT) from Universidade Nova de Lisboa. She received her $\mathrm{PhD}$ in Business Administration from the Institute of Economics and Business Administration, Lisbon Technical University. Her main interests are in the fields of knowledge management, intellectual capital, strategic management and creative economy. 
Virgílio Cruz-Machado holds a PhD in Computer Integrated Management from Cranfield University, UK. He is a Professor of Industrial Engineering at Faculdade de Ciências e Tecnologia, Universidade Nova de Lisboa, Portugal. $\mathrm{He}$ coordinates the postgraduate programmes in industrial engineering, project management and lean management. His main scientific activities are directed to the design and improvement of supply chain management. He is the President of UNIDEMI and President of the Portugal Chapter of the Institute of Industrial Engineer.

Cristina Cabrita has a degree in Architecture and holds a Master in Management. She is a PhD student at ISCTE-IUL Lisbon University Institute Lisbon, Portugal. Her research interests are in the fields of architecture, creative economy, creative industries and urban regeneration.

This paper is a revised and expanded version of a paper entitled 'The role of creative cities in the context of sustainable urban development' presented at the Second Edition of the MSKE Conference, Universidade Lusiada de Famalicão, Portugal, July 2011.

\section{Introduction}

In the era of knowledge, sustainable economic growth and prosperity are highly associated with knowledge-based economies (Metcalfe and Ramlogan, 2005) where cities and regions are increasingly becoming critical agents of development.

Cities and regions, depicted as intelligent, connected and networked entities, throw themselves into the roles of entrepreneurs, artists and intellectuals, becoming the focus of interest for a wide group of professionals and local authorities. Economic development and urban planning practitioners around the world are focusing on the producers and consumers of the creative economy as the basis for growing successful cities. In tune with these changes are the notions of knowledge management applied to cities and regions which have brought paradigmatic shifts in the way we live, work and learn in urban communities around the world (Garcia, 2008).

As mentioned by Yigitcanlar (2008), creative cities and knowledge cities are the first urban formation tailored for the needs of a knowledge-based economy where ideas flourish and nurture innovation and wealth creation. In this sense, the advantages of a creative city or a knowledge city at a global, national, regional or local scale cannot be ignored by policy-makers, local or regional authorities, private sector, or social organisations. In such context, policy-makers have to situate the creative industries at the heart of knowledge economy concerns and to develop policies accordingly. It focuses on the key content generating parts of the creative industries but also points to the wider role of creative assets (products and services) across a value range that stretches from economic growth and social cohesion.

Knowledge-based urban development (KBUD) is a strategic development approach that aims to make urban spaces compatible with the knowledge economy. An economy, environment and socio-cultural base strong in knowledge are the keys for transforming those urban spaces into a knowledge city or region. The KBUD provides a framework to guide the evaluation of enabling conditions for cities competition in global market. 
According to Carrillo (2006) these conditions include knowledge infrastructure (e.g., universities, research and development institutions); technological infrastructure [e.g., information and communication technologies (ICTs)]; connections to the global economy (e.g., international companies and financial institutions); and concentrations of well-educated and creative people (e.g., knowledge and creative workers). Consequently, urban spaces are incubators of knowledge and culture. The KBUD is a multidisciplinary concept that has been receiving rich contributions from other disciplines such as economics, urban studies, geography, neuroscience, social studies and psychology, among many others. How KBD approach can help to identify the factors contributing to cultural sustainability is essential to formulating regional strategic plans. Raza et al. (2006) argue that the global successful application of the KBD strategy is closely tied with the cultural, the ecological, the economic and the ethical pluralities of the human communities. The authors state that the KBD strategy can play a fundamental role in the social transformation and the economic development if the former is well integrated with the cultural values of the local people.

There is a lot in common between creative industries, KBD and KBUD due to the emphasis given to knowledge, creativity, R\&D, investment in ICT and education as the key drivers of growth and prosperity in the contemporary economies. In the KBD the key to a sustainable competitive advantage for a firm is to create and apply knowledge. The source of value relies on the issues of acquiring, creating, developing, storing and applying knowledge. KBUD is namely about processes of knowledge production, including urban governance, development and planning, and is considered a new strategic development approach in the context of a global economic competition (Yigitcanlar et al., 2008). The main promise of KBUD policy is a sustainable urban and economic development based on the following pillars: providing hard and soft infrastructures, retaining financial support, promoting social and human capital systems, developing and adopting the state of art technologies, and providing quality life and place (Carrillo, 2004; Yigitcanlar et al., 2008).

As emerging fields of study and practice, creative industries and KBUD have become crucial aspects of success in the tough global competition of attracting talents (Florida, 2005), developing regional intellectual capital (Edvinsson, 2006b), and retaining knowledge-intensive industries (Yigitcanlar, 2009). This work may provide some clues on the direction that the integration of 'creative industries' field can take in the context of the KBD, promoting cultural sustainability. The presence of a creative class is essential to make happen and sustain creative clusters.

This paper first explores the importance of knowledge and creativity as key resources in contemporary societies. The second section examines some characteristics of KBUD. It follows with an overview of connected concepts such as 'creative economy', 'creative industries', 'creative cities' and 'creative class' in an effort to reach not a final consensus but at least a shared vision as a basis for comparative analysis and informed policy-making. In the fourth section we explore the broader sense of sustainable development. The fifth section depicts a template which emphasises some of the major driving forces for nurturing and sustaining creative industries a source of sustainable urban development. It follows with discussion and policy implications on the subject. In conclusion, this paper contributes to discussions on how creative industries-creative class linkages and a KBUD focus can support creative economy and promote cultural urban sustainability. 


\section{Knowledge and creativity as key resources in contemporary societies}

Knowledge, innovation and creativity are the main driving forces behind economic development in today's world. This has shifted development perspectives from tangiblesbased competitiveness to knowledge-driven competitiveness giving birth to new development paradigms. In the knowledge-driven economy, sustainable competitive advantage comes from creative, innovative and sophisticated use of knowledge and intellectual capital as strategic factors that enable dealing with the challenges of a turbulent, complex and dynamic global environment.

OECD (1996) defines knowledge-based economies as those that make effective use of knowledge for its economic and social development. Managing knowledge becomes the fundamental activity of organisations in a context where some argue that "the industries of the twenty-first century will depend increasingly on the generation of knowledge through creativity and innovation" [Landry and Bianchini, (1995), p.4].

In such context, the process of innovation becomes one of the ultimate managerial and political challenges of the next decade. It is at the heart of business survival, economy transformation and prosperity sustainability. Innovation is critical not only for business but also in civic domains, such as cities and regions. The quest for innovation is relevant not only to economic sustainability but also to social and cultural life. Therefore, the creation of an urban environment which enables and catalyses knowledge, innovation and creativity have gained great influence and popularity in political discourses.

While creativity is becoming an important input into the production process of goods and services, it may also be particularly useful in the knowledge-based economies to convert scientific and technological knowledge into market value. Over the past ten year, an increasing realisation that the convergence of technology and content provide growth and distinctively competitive market positions, have made culture and creativity an increasingly key focus for regions and cities providing the leading edge for their tourist industries, offering a 'creative brand' to attract inward investment, and providing new skills and identities that may bring with them a unique, competitive edge.

In this context, the process of innovation becomes one of the ultimate managerial and political challenges of the next decade. It is at the heart of business survival, economy transformation and prosperity sustainability. Innovation is critical not only for business but also in civic domains, such as cities and regions. The quest for innovation is relevant not only to economic sustainability but also to social and cultural life. Therefore, the creation of an urban environment which enables and catalyses knowledge, innovation and creativity have gained great influence and popularity in political discourses.

For a long time, research on creativity has been a domain of psychologists due to the fact that creativity is an attribute of personality. Only recently, scholars of other research fields such as psychology, sociology, education science, biology, economics, geography, and organisational science have made significant contributions to this topic. In organisational literature the term 'creativity' is associated with originality, inspiration, imagination and inventiveness. In the context of economic development it refers to the formulation of new ideas and to the application of these ideas to the production of original works of art and cultural products, functional creations, scientific invention and technological innovations. 
Creativity has the ability to benefit almost all economic sectors. The challenge for all industry is to think creatively, to constant reinvent itself, to bring new and value-added design that will result in unique, distinctive and original products and services.

There is no simple definition of creativity that encompasses all the various dimension of this phenomenon. Recognising its complex nature, Rosen (1987) refers to creativity as part of a person's human capital, i.e., her or his strengths and intangible assets such as knowledge, skills, general intelligence, educational attainments, or personality characteristic. In the context of knowledge-based economy, the most common approach is to consider creativity as a result of cultural creativity, scientific creativity, economic creativity and technological creativity, as depicted in Figure 1. Cultural creativity embraces imagination and a capacity to generate original ideas and novel ways of interpreting the world expressed in text, sound and image; scientific creativity involves curiosity and a capacity to develop new connections in problem-solving; economic creativity refers to a dynamic process that leads to innovation in products/services, business practices, closely related to gaining sustainable competitive advantage; technological creativity is interrelated to all other kind of creativity, because technology is part of any other type of creativity.

Figure 1 Creativity in knowledge-based economy (see online version for colours)

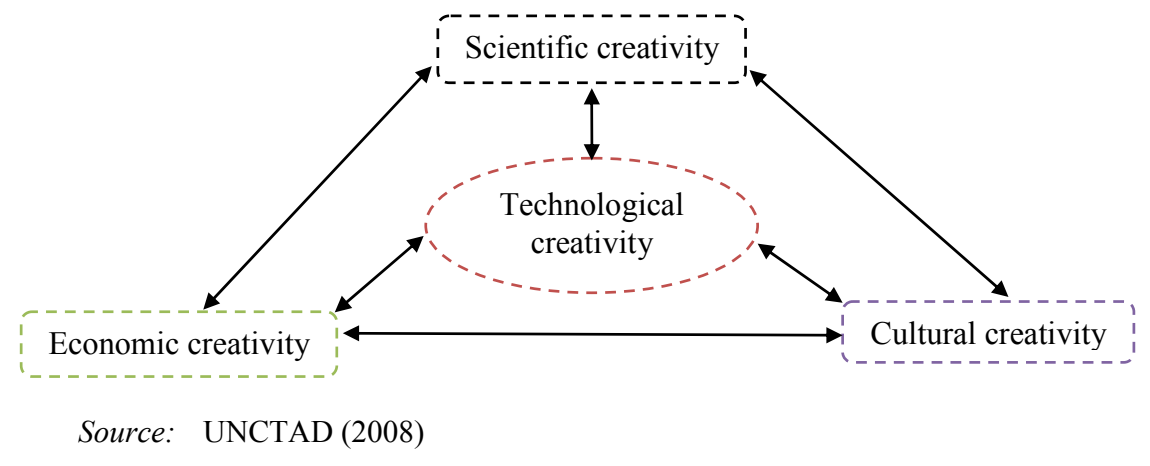

Creativity is a complex process of innovation combining some of all of the following dimensions: ideas, skills, technology, management, production processes as well as culture. Being a product of the mind, creativity has a fundamental intangible dimension. The creative product derives its value from the artistic and human talents incorporated in it at different stages: creation, production, reproduction and distribution.

Different theories exist describing the role of creativity in contemporary societies. It is not the aim of this paper to develop such theories, but we focus our work on the idea that creativity is a prominent guideline of social and economic life, therewith (re)shaping the social structure of society in a certain way. Florida (2002, p.7) formulated what he called the Rise of the Creative Class, announcing the advent of a new economic class - the Creative Class -, described as 'the norm-setting class of our time'. To his mind, creativity is a human ability that everyone can use for life and work. In this sense, everyone can potentially become a member of the creative class. Additionally, Florida considers creativity as a central value of contemporary societies and identifies the creative class as the key drivers of the knowledge economy. As mentioned by Rijn and Tissen (2007), the shift toward a knowledge economy is largely regarded to be a shift from 'intellectual-industrial' workers to 'creative-conceptual' workers. 


\section{Knowledge-based urban development}

The origins of KBD can be traced back to influent disciplines such as economics, urban studies planning, anthropology, psychology, social sciences, architecture, political economy, innovation management, information and technology management and knowledge management.

The World Bank has introduced a knowledge-based framework at the national level called the knowledge-based economy which consist of four pillars - education; science and technology, and innovation; ICT infrastructure; and economic incentive regime. The Asian Development Bank expanded this knowledge-based economy framework to include the application of knowledge management to socio-cultural and natural-environmental domains. The resulting framework is called knowledge-based development (KBD) which intends to reflect the combination of two powerful development paradigms: sustainable development and knowledge-based management. Evidences in the field of KBD are flourishing day by day at different levels: urban (Singapur, Barcelona); regional (Veneto, Basque Country); national (Denmark, Australia, New Zealand); and supranational (European Union).

Since the early 1990s, researchers and policy-makers in advanced economies have focused on KBD as a means to stimulate economic growth (OECD, 1996) and sustain industrial competitiveness. In this perspective, KBD concentrates on strategies and alternative pathways for creating urban 'centres of excellence', building up an effective information structure, providing generalised access to networking, and reducing backwash effects in respect of knowledge and skilled labour.

Under the umbrella of KBD, other topics, such as 'KBUD', 'creative economy', 'creative industries', 'creative cities' or 'creative class' have attracted the interest of governments focusing on the qualitative aspects of development in order to establish a creative environment for local people and businesses, reintegrate the knowledge sector as a whole, and facilitate channels of exchange.

In literature abound the concepts, theories and methods relating to these themes however they are not yet fully developed. For each topic a number of definitions or clarifying concepts by one or more authors may be provided. Many of the terms are similar in meaning because they present the same idea according to different points of view or they describe projects at different levels of government. The KBD approach will have profound implications for trade, growth and prosperity of regions, cities and communities. Most advanced economies rely heavily on services, information, technology and intellectual property. Along with the dominance of these industries comes the need for greater creativity and innovation in their human capital. The more traditional industries can also benefit from the existence of talented and creative people. Generally speaking, the quantity and quality of human capital will determine the parameters for success. Such phenomenon breeds competition for people, ideas, businesses and quality of life, influencing and shaping the competitive performance of regions.

The Journal of Knowledge Management dedicates each year, since its first attempt in 2002 as Vol. $6 \mathrm{~N}^{\mathrm{o}}$ 4, a special issue to the KBD topic. Since then, KBD models of various types have been proposed, analysed and criticised (Carrillo, 2006). As Knight (2008) refers, engineering and orchestrating the development of creative urban regions is not an easy task to undertake. Besides a strong economy, organisation skills, knowledge pool for talent and investment, socio-cultural vibrancy, technological capacity of society, rich natural, physical and knowledge assets and amenities, it also requires a new 
understanding and perspective in what concerns physical, economic and social development dynamics of cities (Baum et al., 2007). In addition, the diversity of human cultures requires holistic and socially sensitive perspectives of development, which also take into consideration the critical relationship of human values and their impact upon the global economic development (Raza et al., 2006).

According to Yigitcanlar (2009), KBUD is a new strategic development approach in the scope of the global economy competition. It is namely about processes of knowledge production, and their impact on the urban form and functions, which provides a new perspective for the development of creative urban regions. KBUD involves contemporary understanding of value dynamics, capital systems, urban governance, development and planning.

Figure 2 Three pillars of KBUD (see online version for colours)

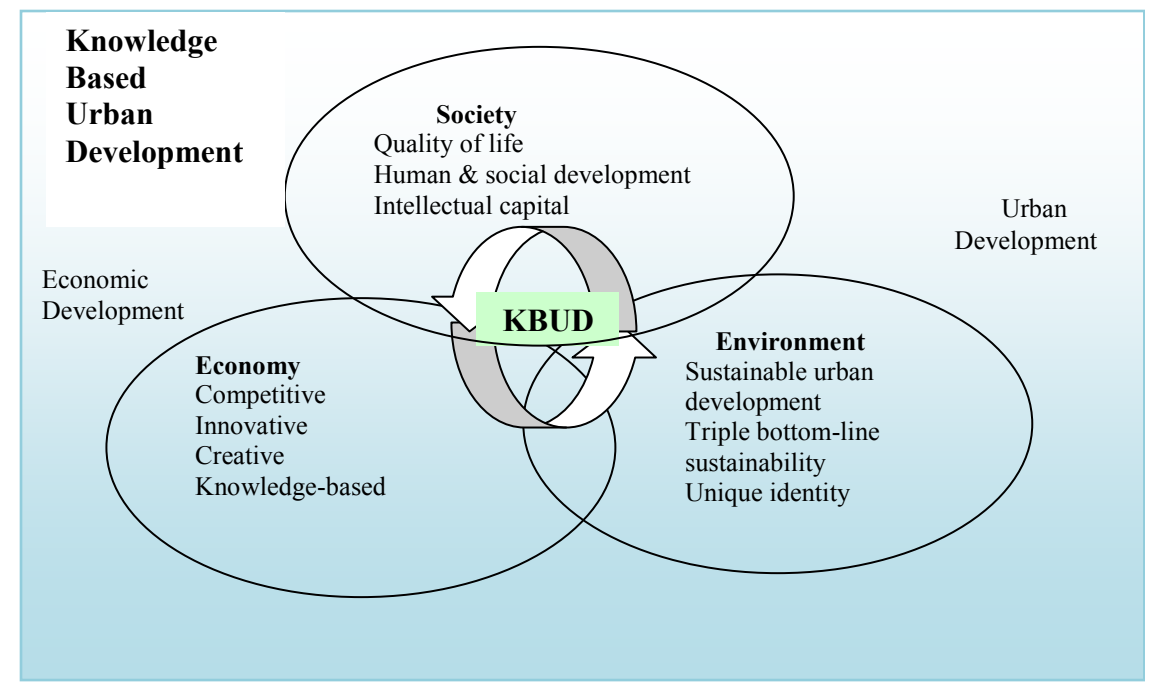

Source: Yigitcanlar and Velibeyoglu (2008, p.298)

As mentioned by Yigitcanlar and Velibeyoglu (2008), KBUD transcends many of the economic, social and urban policies. The authors developed a framework, as shown in Figure 2, grouping relevant areas into what they consider the three pillars of urban development.

First, KBUD is an economic development strategy that supports:

- codification of technical knowledge for the innovation of products and services

- market knowledge for understanding changes in the economy

- financial knowledge to measure the inputs and outputs of production and development processes

- human knowledge in the form of skills and creativity.

This first pillar supports a local economic development that is competitive, and integrates the knowledge-based economy principles.

Second, KBUD is oriented to the societal development improving the means to increase the skills and knowledge of residents and employees, necessary for intellectual, 
human and social urban development. This second pillar aims to improve the quality of life by providing products and services for societal development.

Third, KBUD builds and promotes an environment where relationship among urban development clusters may expand their knowledge base that contribute significantly for the establishment, reinforcement and sustainability of creative urban regions. This third pillar aims to promote an ecologically and sustainable urban development.

More recently, Sarimin and Yigitcanlar (2012) compares most relevant existing KBUD models to identify key and common features contributing to urban development.

\section{Understanding the creative economy}

Fundamental to an understanding of the creative economy - how it functions and what it comprises - are the concepts of creative industries, creative cities and creative class. Much debates surrounds these terms, emerging, at the same time, innovative notions such as 'creative commons' and 'creative ecology' (UNCTAD, 2010).

There is no unique definition of the 'creative economy'. It is a subjective concept that is still being shaped. For some, it is a holistic concept embracing complex interactions between economics, culture and technology that are dominated by symbols, texts, sounds and images. Others, more sceptical, advocate some concerns about its exacerbated importance. Meanwhile, the creative economy has become a hot topic on the international economic and development agenda in both developed and developing countries.

Regions and cities are seen as dynamic locales of experimentation and innovation, where new ideas flourish and people come together to make their communities' better places to live, work, and play. They engage different knowledge, value holistic thinking, and act on the interdependence of economic, social, environmental and cultural goals.

An increasing number of states are recognising a creative sector approach as a useful and timely part of the solution to a changing economy.

\subsection{Creative economy}

The term 'creative economy' was coined by John Howkins in 2001 in a book devoted to the study of relationship between creativity and economics and the way they combine to create extraordinary value and wealth.

There is no universal definition of the term 'creative economy'. Still being shaped, it is a holistic concept embracing complex interactions between economics, cultural and social aspects interacting with technology, intellectual property and tourism objectives. UNCTAD (2004) refers to the creative economy as an evolving concept based on creative assets potentially generating economic growth and development. It is a set of knowledge-based economic activities with a development dimension and cross-cutting linkages at macro and micro level to the overall economy.

Because of its potential economic and social benefits, the creative economy has become a hot topic on the international economic and government development agendas in both developed and developing countries.

Howkins (2001, p.xiv) refers to the creative economy as comprising "financial transactions in creative products... whose raw material is human talent". Regarding the creative economy as the new basis for wealth creation and economic growth, Howkins (2001, p.ix) writes: "people with ideas - people who own ideas - shave become more 
powerful than people who work machines, more powerful than people who own machines". Therefore, he asserts, "the creative economy will be the dominant economic form in the twenty-first century". In the same vein, Carrillo (2006) calls the 21st century the 'century of knowledge cities' since creative cities and knowledge urban regions have become centres of knowledge generation, with specific conditions to support a KBD.

The creative economy is broadly defined as the sum of economic activity arising from a highly educated segment of the workforce encompassing a wide variety of creative individuals - like artists, architects, computer programmers, university professors and writers from a diverse range of industries such as technology, entertainment, journalism, finance, high-end manufacturing and the arts.

The term 'creative economy' is seen as an umbrella to encompass economic development initiatives with arts or cultural dimensions. The literature shows that states define their creative economies in a variety of ways, depending on the composition and character of businesses, non-profits, individuals, and venues that exist in any given area. Therefore, there is a consensus that individual states should develop definitions that are appropriate to their unique circumstances and own reality.

The scope of the creative economy is determined by the extent of the creative industries. Moreover, an important point to consider in the creative economy is the classification of creative assets. In 1986, UNESCO published its framework for cultural statistics. This defined ten categories:

1 cultural heritages

2 printed material and literature

3 performing arts

4 visual arts

5 audiovisual

6 media

7 socio cultural activities

8 sport and games

9 environment

10 nature (UNESCO, 1986).

UNESCO's focus is on cultural diversity in developing countries and countries in transition to a market economy. UNESCO tries to standardise a methodology for statistics on arts and creativity and highlights the following policy issues: copyright, fiscal schemes, technological infrastructure, capacity building, promotion activities, investment, export strategies and international partnerships.

\subsection{Creative industries}

In 1997, the Blair Government established the Creative Industries Task Force (CITF) and began advancing the proposition that the most successful economies and societies in the 21st century would be creative ones (CITF, 2001). The paradigm shift has been recognised by economists such as Sveiby (1997), Howkins (2001), Viedma (2003), 
Edvinsson (2006a), among others, who advocate that knowledge and creative production, exchange and application are now moulding the global economy.

Like Howkins, Florida (2002) has recognised that diverse sectors have the capacity to supply creativity. Within these sectors the 'human talent' operates as micro businesses or individual artists, important producers of goods and services in every state's cultural economy. It is through the work of individual artists that cultural goods are produced, small businesses are started, and innovative design ideas enter into the marketplace. To support this role, many states are using small grants to encourage entrepreneurship, new product development, and career advancement among artists and creative individuals.

The term 'creative industries' is of relatively recent origin, emerging in Australia in 1994 with the launching of the report, creative nation. It was given wider exposure by policy-makers in the UK in 1997, when the Government, through the Department of Culture, Media and Sport (DCMS), set up the CITF.

Definitions of the scope of 'creative industries' vary. The UK's Department of Culture Media and Sport (DCMS, 2005) defines creative industries as "those industries which have their origin in individual creativity, skill and talent and which have a potential for wealth and job creation through the generation and exploitation of intellectual property. These have been taken to include the following key sectors: advertising, architecture, the art and antiques market, crafts, design designer fashion, film, interactive leisure software, music, the performing arts, software, and television and radio".

Emphasising the concept of intellectual property, Howkins (2001) classifies creative industries into four broad subsectors: copyright, patents, trademarks and design.

UNCTAD (2004) associates the creative industries to the cycles of creation, production and distribution of goods and services that use creativity and IC as primary inputs. According to its classification, creative industries comprise a set of knowledgebased activities that produce tangible goods and intangible intellectual or artistic services with creative content, economic value and market objectives.

O'Regan (2002, p.19) states that "the creative industries model configures culture as a service industry and creativity as an application", while Flew (2002, p.8) advocates that "the relationship of creative industries to the knowledge economy, cultural industries and the services industries sector, is central to understanding the dynamics of new economy".

No matter the classification adopted, what seems clear is that the creative industries sector lies at the crossroads between the arts, business and technology and deals with the interplay of various subsectors. A common denominator of all these industries is that aesthetic attributes are key elements of products and service differentiation and value.

The creative industries are networked, organic and flexible and their value resides within the generation and trading of intangibles. In this sense, the creative industries need to be positioned as part of a series of interdependencies that contribute to effective creative place-making. Hasan et al. (2008) found evidence that creative businesses stimulate innovation in the wider economy through their supply chain relationships with business in other sectors.

To gauge the contributions to and potential impact of creative industries on a state's economy it is important for each state to identify its creative industries and measure its creative economy.

The creative economy capitalises on cultural assets including buildings, institutions, organisations and people. States should then conduct a comprehensive scan of their cultural assets and include creative industries in their cluster analyses. To get started, 
approaches should be addressed for better identifying and analysing the cultural resources so that state policymakers may better understand the existing creative industries in their state and the dynamic roles that these enterprises play in the state's economy.

To fully understand the economic contributions of those industries it is crucial to categorise the relevant group of assets in creative industries. In this context, we purpose that creative industries include human, institutional, physical, organisational and social assets, as shown in Figure 3.

Figure 3 Conceptualising creative industries (see online version for colours)

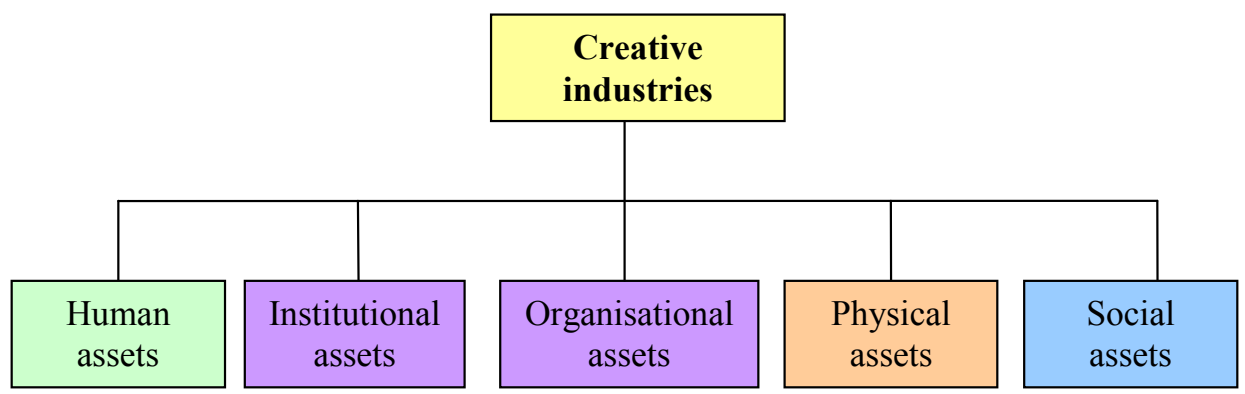

Human assets comprise talented individuals and creative professionals who work in a wide range of knowledge-intensive industries. For the purpose of this paper, we adopt the Florida's definition of creative class. Institutional assets refer to cultural and government institutions that study encourage and support the integration of culture-related industries into their state's economic development strategies. These include offering incentives targeted at the arts and creative industries as well as development initiatives, entrepreneurial training and marketing programmes. Organisational assets are those related to companies, economy and management. Physical assets include buildings, museums, gardens, etc. Social assets are the relationships established between the governors, individuals, institutions and companies. It is about communities, collaborative teams and public-private collaborations.

The creative industries while economically important, they are also about:

- resources of identity

- resources of social inclusion/cohesion

- economy of symbols, values and meanings

- quality, vitality and conviviality of lived human environments

- resources of a sustainable and creative new economy

- development of distinctive local, regional and national identities in the context of globalisation and potential homogenisation of cultures.

There is a consensus in the literature that it is better to think about the creative industries at the local and regional levels 


\subsection{Creative cities}

Knowledge has always played an important role in the creation of wealth and organisation of life, and has been at the core of city development since the dawn of civilisation. It is only recently, however, that knowledge and creativity have been recognised as primary factors that drive city development. Recently, some studies emphasise how knowledge must be embedded in society contributing to sustainable cities (Thorpe et al., 2012).

Many cities around the world started to view knowledge, innovation and creativity as keys to development and economic prosperity, and adjusted their urban planning and endogenous strategies to the features of and ultimate goals of KBD. With the advent of an increasingly global society, greater attention has to be given to the cities' cultural assets and to their role as knowledge centres.

The concept of creative cities offers advantages to any sustainable urban development region. Creative cities are dynamic locales of learning and innovation, where new ideas flourish and people come together to make their community better places to live, work, and play. They engage different kinds of knowledge, and encourage widespread public participation to deal imaginatively with complex issues. Martinus (2012) investigates how local-global linkages and social capital building capacity of five mid-size cities support innovation and knowledge development.

In such context, the implementation of creative cities projects, all over the world, in recent years, has been characterised by a great diversity of institutional frameworks and governance mechanisms.

Despite the developments on this area, Landry (2000, p.8) adverts that we now need "real models to show what is meant by the creative city". Edvinsson (2006a) develops the perspective of a city and its design as a knowledge tool. The author argues that the city concept and design of its new urbanism is becoming more and more a strategic tool in the global competition for knowledge or talent war. Furthermore, Edvinsson (2006b) observes that the creation of wealth in an economy of ideas is closely linked to intellectual capital for individuals and for organisations - private or public -, and is also linked to structural capital of cities, communities and nations.

\subsection{Creative class}

The creative economy is driven by the creative class (Florida, 2008), a class of workers whose job is to create new forms and ideas which will become realisable economic assets. According to Florida (2002) and Howkins (2001) intellectual property or creativity is paired with creative class. The creative class, represented by talents, constitutes the core of innovative industries. They are both a collective asset to a society and an economy as well as the labour force which produces knowledge.

The creative class is wide-ranging and includes mathematicians and musicians, software designers and lawyers, poets and sociologists, economists and engineers, chemists and novelists, artists, physicists, psychologists and architects. These are all professions which are knowledge intensive, they are careers usually require a high degree of formal education, skills acquisition or apprenticeship. Edvinsson (2006a) refers to 'creative class' as the equivalent to ore for the industrial society, the most attractive input of the knowledge economy. 
Based on empirical investigations, Florida and Gates (2002, p.32) conclude that “...a city's diversity - its level of tolerance for a wide level of people - is the key to its success in attracting talented people".

The Florida's three Ts - talent, technology and tolerance - focus on new combinations of artistic or cultural creativity with business entrepreneurship and technological innovation. The resulting synergies, he argues, are the key to prosperity in an age of knowledge-based production. And they only occur in those localised settings where 'talented' people choose to live and meet professionally in networks. Three conditions distinguish these cities as the new economy's pivotal 'creative milieux'.

First, they have thick labour markets with rich opportunities for knowledge workers arising from spatially proximate technology firms, venture capitalists, universities and research institutes. Second, they have well developed and attractive urban amenities - preserved natural and built environments - suited to the recreational preferences and aesthetic sensibilities of younger professionals. Third, the urban culture is defined, on the one hand, by its tolerance of diversity, and on the other hand, by the vibrancy and local flavour of its street scene reflected in cafés, clubs, music, theatre, design, and fashion. Where these three conditions intersect, Florida finds clusters of creative industries and imaginative reuse of urban space. Based on these assumptions, Figure 4 depicts the platform that nurtures and sustains creative industries.

Figure 4 The platform of creative industries (see online version for colours)

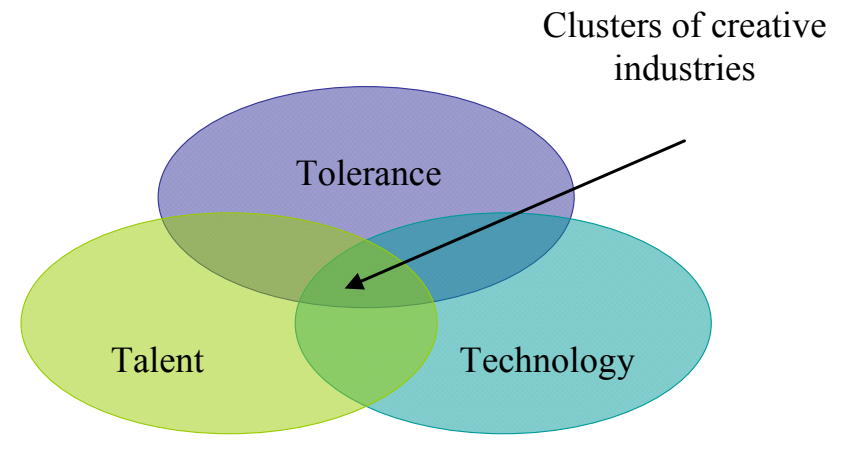

\section{Sustainable development and a sustainable society}

Sustainable development is a popular and important concept, but one that is difficult to define. A great number of alternative definitions of sustainable development exist. The concept of 'sustainable development' was popularised as a normative goal by the World Commission on Environment and Development in their 1987 report to the General Assembly of the United Nations, Our Common Future (World Commission on Environment and Development, 1987). There, sustainable development was defined as a development:

- that meets the needs of the present generation

- that does not compromise the ability of future generations to meet their own needs 
- $\quad$ in which each individual has the opportunity to develop himself in freedom, within a well-balanced society and in harmony with its surroundings.

This definition suggests the need to balance two concerns, one having to do with present, or intra-generational needs and the other having to do with future, or inter-generational needs.

In essence, sustainability is about the quality of life and the possibilities for maintaining this quality in future. "What sustainability is, therefore, depends on public opinions about quality of life, the distribution of this quality across the globe, and the scientific understanding of the functioning of humans and natural systems" [RIVM, (2004), p.5]. This definition refers to the quality of life and the possibilities of maintaining these qualities for future generations. What sustainability is, therefore, depends on public opinions about what quality of life is. This means that we should try to find what sustainability means for us and for other groups, and how to reach this goal in a scientific way. The challenge is to think and promote a region development based on three target areas: social solidarity, economic efficiency and ecological responsibility. Every state strives to support the prosperity and productivity of its people and its communities. In this context, it is urgent to indicate the direction to be taken in order to create and maintain a sustainable society.

An increasing number of states are recognising a creative sector approach as a useful and timely part of the solution to a changing economy. Increasingly, place-making strategies focus on their cultural offer and on the presence of cultural infrastructure and a dynamic creative industries sector. This means that by helping to create positive images, vibrancy and distinctiveness, the creative industries sector has a direct impact on inward investment and the attraction/retention of skilled knowledge workers.

The literature and case studies demonstrate that creative cities contribute significantly to meeting important local and national policy goals ranging from economic innovation to social citizenship and environmental sustainability. Clearly, all governments have an important stake in supporting initiatives that make cities creative. Kuan Yew (2000, p.691) state that the basic principle for the progress of Singapore is "social cohesion through sharing the benefits of progress, equal opportunities for all, and meritocracy, with the best man and woman for the job, especially as leaders in government".

According to the European Commission (2010a), The Capitals of Culture Project, inaugurated in 1985, seeks to highlight "the wealth and diversity of European cultures", promote "mutual understanding between European citizens", and "encourage a sense of belonging to the same European family by making us aware of our common European roots and our shared ambitions for the future".

A point to emphasise is that sustainability is not just about the environment. A sustainable society must be just and equitable, and provide opportunities for each member of the community to reach his/her potential. A sustainable society provides access to work, play, healthcare, education and so on, for each of its members.

\section{The role of creative industries in sustainable urban development}

As mentioned above, the KBD model comprises three pillars: economy, society and environment. In this scenario, culture has an integral role in sustainable development. 
Within the sustainability field, culture is often discussed in terms of cultural capital, which goes beyond arts and heritage to encompass diverse traditions, values, place, and social history. The stock of cultural capital, both tangible and intangible, is what we inherit from past generations and what we will pass onto future generations. In this sense, cultural sustainability means change occurs in a way that respects cultural values.

Goede (2009) discusses the factors involved in developing and attracting the creative class in the case of Curaçao, a small Caribbean island, and concludes that the main reason that Curaçao has not developed into a creative economy is because there is no shared vision of how this should be achieved. Further, he explains that the government needs to understand the importance of the creative class and implement policies to support its functions, by focusing on institutional arrangements and on people, ideas and technology and not weaken the vital factors.

Some case studies reveal that non-profit cultural organisations have an important role in the education and training of creative individuals or as incubators for enterprises that make up the creative sector. Many arts organisations are not-for-profit - which includes a wide variety of performing groups, arts centres, guilds, museums, performance venues, festivals, and school programmes - but are important to include in an analysis because they serve as assets for attracting and retaining the 'creative class' and provide aesthetic value to the community.

UNESCO (2005) states that to develop a cultural economy, all relevant government agencies, civil society and the private sector must be involved. In addition, Kuan Yew (2000) emphasises the role of meritocracy in promoting talents and capabilities in cities.

Then, the main actor of creative economy is the creative class and some factors are identified as contributing to the rise of the creative class:

1 Institutional framework: this includes legal system, the protection of property rights and intellectual property, political stability and judicial system. Furthermore, intermediary institutions have an essential role to play in helping to build trust and understanding of objectives and expectations of citizens.

2 Meritocracy: appointing people based on their talents and capabilities. Such a system, in theory, forms the basis of an 'equal opportunity' society.

3 Real estate and old buildings: as a rule, creative industries build upon a rich and diverse core of cultural heritage and skilled artists. In this respect, an attractive real estate market and the availability of old and historic buildings offer opportunities to concentration of creative people.

4 Entrepreneurial initiatives: the dynamic process of new firm creation introduces and disperses innovative products processes, and organisational structures throughout the economy. A diverse range of entrepreneurs and the free movement of their services is a pre-requisite for a culturally diverse offer to consumers.

5 The level of education of people: creative industries are knowledge-driven industries that tend to gravitate towards specialised labour markets. International studies refer that the knowledge economy becomes feasible if $50 \%$ of the working population has a higher education background.

The popular literature on creative industries has been largely dominated by the work of Richard Florida. Economic development, according to Florida, depends on a region's ability to foster the three T's ingredients: tolerance, talent and technology. A tolerant area 
attracts diverse people with different sets of ideas and skills. Diversity and concentration, in turn, speed the flow of knowledge. This increase in knowledge creates a base of creative capital - the education, skill development and training that incubates creative thinking. Over time, the talented workers of the region create reputation among individuals and with stimulating interaction, individuals move to this area. Then, in order to take advantage of an educated and creative class, businesses follow.

Figure 5 Factors promoting cultural sustainability (see online version for colours)

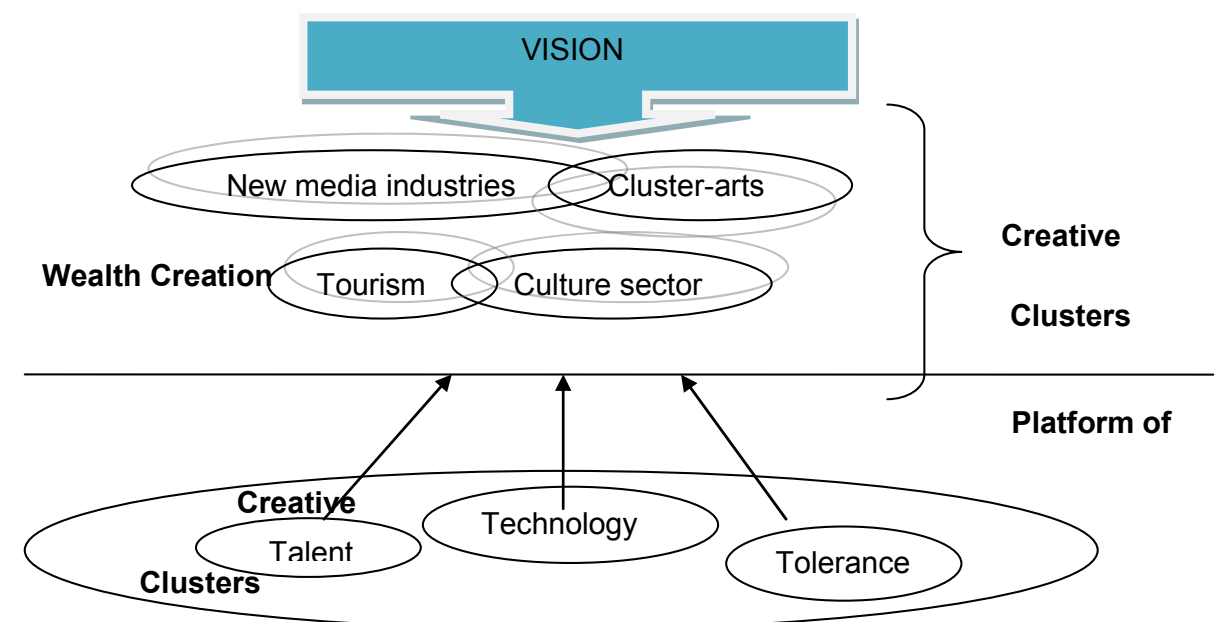

Factors contributing to the rise of creative class

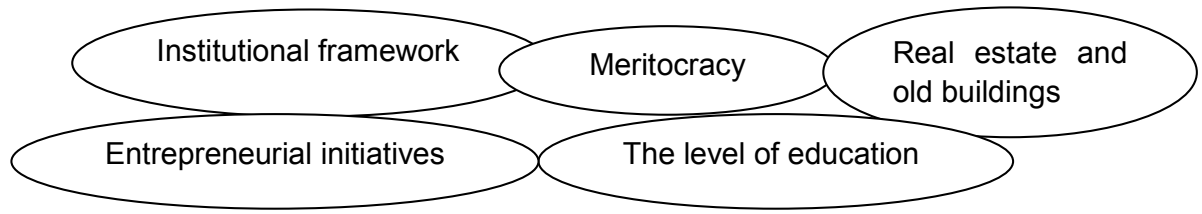

The popularity of Florida's work has led to a zealous implementation of his creative class thesis by many policymakers and urban planners. In his influential work, Florida argues that "creative professionals (including managers, researchers and scientists) tend to be attracted to cities or communities sharing a rich cultural life and tolerance for alternative lifestyles. Academic research suggests that large scale industrialization of creativity and cultural innovation occurs in large urban areas" (European Commission, 2010b).

Creative clusters generally emerge organically in specific urban frameworks through relations of production, work, research, education, entertainment and leisure. Creative clusters have been defined as a combination of production and distribution activities operating within a common structure, capable of promoting creativity, research applications and distribution systems, and sponsored by both private and public financing. They are seen as a concentration of competitors working together, or dissimilar workers and institutions that share an economic system. 
From the revision of literature, a tentative template emerged in Figure 5, which highlights some of the major driving forces for nurturing and sustaining creative clusters surrounding citizens, a source of sustainable urban development.

\section{Discussion and policy implications}

Linking creative economy concepts and the KBUD mechanisms is a development approach that aims to make creative industries compatible with the knowledge economy. Creative industries are seen as a source of innovation for the knowledge economy and the KBUD mechanisms offer citizens opportunities to foster knowledge creation, knowledge exchange and knowledge application promoting creativity and innovation.

Incorporating the creative economy concepts in the KBUD strategies is a complex task due to the fragmented concepts and cross disciplinary approaches can be taken. The creative economy extends to almost all areas of government policy, calling for an integrated cross-cutting approach. Our work aims to focus on enabling conditions for the emergence of creative clusters and cultural sustainability, based on the Florida's elements. However, other approaches are referred in the literature. The UNESCO Report (2012) on Culture: a driver and an enabler of sustainable development states that cultural heritage, cultural and creative industries, sustainable cultural tourism, and cultural infrastructure can serve as strategic tools for revenue generation, particularly in developing countries given their often-rich cultural heritage and substantial labour force. The Report recommends policymakers and governments to integrate culture in the development agenda and for that, clear objectives, definitions, mechanisms, tools, monitoring and evaluation systems are needed.

Academic research suggests that large scale industrialisation of creativity and cultural innovation occurs in large urban areas (European Commission, 2010b). Creativity and innovation have a strong and distinctive regional dimension. Policies and support instruments need to be determined locally (a place-based development approach), building on local specificities and assets and tapping into local resources. At the same time, effective coordination between different policy and administration levels is essential for success. Impact assessment and evaluation tools should be built into development strategies to support the design of evidence-based policies.

The most important contribution of this paper for policymakers is to purpose an approach to integrate culture into governance, focusing on attraction and support of creative class where conception and practice of development is formulated with a view to inclusive and sustainable development. However, other factors should be analysed such as financing support and legal policies.

\section{Conclusions}

The KBUD framework provides a clear understanding on identifying and managing local creative industries. Creativity is one of the vital sources for attracting investment and talent that drive the economic vitality of a city.

Creative cities play an important role in the knowledge economy and may be seen as an opportunity for reinvention. The culture-generating capabilities of cities are being harnessed to productive purposes, creating new kinds of localised competitive advantages 
with major employment and income-enhancing effects. Therefore, the transformation of cities is facing a new challenge that is to maintain the innovation leadership in a context of crisis. Essentially this means cities' future opportunities as a cultural reservoir, as a cultural producer and as a citizen's cultural project.

The creative city strategy is not only recognised the importance of creativity and creative industries, but also urban development and renewal, ecological sustainability, and development of social and human capitals.

Creative cities such as Barcelona, Copenhagen or Aston demonstrate that local policymakers can play an important role in preparing cities for the requirements of the knowledge economy, particularly, preparing communities for developing its urban competitiveness. The culture-generating capabilities of cities are being harnessed to productive purposes, creating new kinds of localised competitive advantages with major employment and income-enhancing effects.

We argue that 'creative economy' concept help us to broad the idea of 'sustainability'. If crisis is defined as the inability of a system to reproduce itself, then, sustainability is the opposite: the long-term ability of a system to reproduce. This criterion applies not only to natural ecosystems, but to economic and political system as well.

Ultimately, creative concepts are sustained by high quality economic growth, being creative cities centres of industrial growth and cultural expression. Communities should be the primary locus of responsibility for creating a sustainable society and creative cities have to prove to be innovative new ways to promote social and economic development.

We argue that much more research is needed to better understand how the 'creative economy' concepts contribute to a sustainable urban development. There are specific challenges relating to the identification, developing and managing of creative industries within a region or city and these relate to critical assets (human, institutional, organisational, physical and social), key elements of the KBUD pillars.

\section{References}

Baum, S., Yigitcanlar, T., Horton, S. and Gleeson, B. (2007) The Role of Community and Lifestyle in the Making of a Knowledge City, Griffith University, Brisbane.

Carrillo, F. (2004) 'Capital cities', Journal of Knowledge Management, Vol. 8, No. 5, pp.28-46.

Carrillo, F. (2006) 'The century of knowledge cities', in Carrillo (Ed.): Knowledge Cities: Approaches, Experiences and Perspectives, Butterworth-Heinmann, New York, NY.

Creative Industries Task Force (2001) Creative Industries Mapping Document, Department of Culture, Media and Sport [on line] http://www.culture.gov.uk/creative/pdf/part1.pdf (accessed 10 March 2011).

DCMS (2005) Creative industries Section, UK Government, Department for Cultural, Media and Support [online] http://www.culture.gov/ukcreative_industries (accessed 10 March 2011).

Edvinsson, L. (2006a) 'Aspects on the city as a knowledge tool', Journal of Knowledge Management, Vol. 10, No. 5, pp.6-13.

Edvinsson, L. (2006b) 'K-city and society entrepreneurship for intellectual capital growth', in Carrillo, F.J. (Ed.): Knowledge Cities: Approaches, Experiences, and Perspectives, pp.59-73, Elsevier, Amsterdam,.

European Commission (2010a) 25 Years of European Capitals of Culture Speech by Androulla Vassiliou; 23 March [online] http://www.euractiv.com/en/culture/creative-cities-centre-eu2020-goals-says-barroso-news-375706 (accessed 29 June 2012). 
European Commission (2010b) Unlocking the Potential of Cultural and Creative Industries, Brussels.

Flew, T. (2002) 'Beyond ad hocery: defining creative industries', paper presented to Cultural Sites, Cultural Theory, Cultural Policy, Second International Conference for Cultural Policy Research, 22-26 January, Wellington: New Zealand.

Florida, R. (2002) The Rise of the Creative Class - and How It's Transforming Work, Leisure, Community and Everyday Life, The Perseus Books Group, New York.

Florida, R. (2005) The Flight of the Creative Class, Harper Collins, London.

Florida, R. (2008) Who's Your City?, Basic Books, NY.

Florida, R. and Gates, G. (2002) 'Technology and tolerance - diversity and high-tech growth', The Brooking Review, Winter, Vol. 20, No. 1, pp.32-36.

Garcia, B. (2008) 'Global KBD community developments: the MAKCi experience', Journal of Knowledge Management, Vol. 12, No. 5, pp.91-106.

Goede, M. (2009) 'Can Curaçao become a creative economy? A case study', International Study of Social Economics, Vol. 36, Nos. 1/2, pp.47-69.

Hasan, B., McVittie, E. and Simmie, J. (2008) Creating Innovation: Do the Creative Industries Support Innovation in the Wider Economy?, March, NESTA Research report, London.

Howkins, J. (2001) The Creative Economy: How People make Money from Ideas, Penguin, London.

Knight, R. (2008) 'Knowledge-based development', in Yigitcanlar, T., Velibeyoglu, K. and Baum, S. (Eds.): Knowledge-based Urban Development, pp.xiii-xxv, Information Science Reference, London.

Kuan Yew, L. (2000) From Third World to First World: The Singapore Story: 1965-2000, Harper Collins Publishers, NY, New York.

Landry, C. (2000) The Creative City, Earthscan, London.

Landry, C. and Bianchini, F. (1995) The Creative City, Demos, London, UK.

Martinus, K. (2012) 'City infrastructure supporting innovation', International Journal of Knowledge Based Development, Vol. 3, No. 2, pp.126-156.

Metcalfe, J. and Ramlogan, R. (2005) 'Limits to the economy of knowledge and the knowledge of the economy', Futures, Vol. 37, No. 7, pp.655-674.

O'Regan, T. (2002) Too Much Culture, Too Little Culture: Trends and Issues for Cultural Policy Making, February, pp.9-24, Media International Australia Incorporating Culture and Policy (102), Griffith University, Queensland.

OECD (1996) The Knowledge-Based Economy, Science, Technology and Industry Outlook, OECD, Paris.

Raza, A., Kausar, A.R. and Paul, D. (2006) 'Culture, cognition and knowledge-based development', Journal of Knowledge Management, Vol.10, No. 5, pp.137-145.

Rijn, S. and Tissen, R. (2007) 'Building creative cities: towards 'industry-based' knowledge management in urban vision development processes', Proceedings of the 8th European Conference on Knowledge Management, 6-7 September, Spain, Barcelona.

RIVM Report (2004) Quality and the Future. Sustainability Outlook Summary, National Institute for Public Health and the Environment, Bilthoven, The Netherlands.

Rosen, S. (1987) 'Human capital', in Eatwell, J. et al. (Eds.): The New Palgrave: A Dictionary of Economics, Vol. 2, pp.681-690, MacMillan, London.

Sarimin, M. and Yigitcanlar, T. (2012) 'Towards a comprehensive and integrated knowledge-based urban development model: status quo and directions', International Journal of Knowledge Based Development, Vol. 3, No. 2, pp.175-192.

Sveiby, K. (1997) The New Organizational Wealth, Berrett-Kochler, San Francisco. 
Thorpe, G., ArziFard, A. and Kashuk, S. (2012) 'Sustainable cities and the convergence of knowledge', International Journal of Knowledge Based Development, Vol. 3, No. 4, pp.338-401.

UNESCO (1986) Understanding Creative Industries; Cultural Statistics for Public-policy Making, Unesco, Paris.

UNESCO (2005) Towards Knowledge Societies, Paris.

UNESCO (2012) Culture: A Driver and An Enabler of Sustainable Development, UN system task team on the post-2015 UN development Agenda Report, New York.

United Nations Conference on Trade and Development (UNCTAD) (2008) Creative Economy: The Challenges of Assessing the Creative Economy [online] http://unctad.org/en/docs/ditc20082cer_en.pdf (accessed 1 February 2012).

United Nations Conference on Trade and Development (UNCTAD) (2010) Creative Economy: A Feasible Development Option [online] http://unctad.org/es/Docs/ditctab20103_en.pdf (accessed 18 February 2012).

United Nations Conference on Trade and Development (UNCTAD) (2004) Creative Industries and Development (document TD $(X I) / B P / 13$ ), United Nations, Geneva [online] http://www.unctad.org/en/docs/tdxibpd13_en.pdf (accessed 18 February 2012).

Viedma, J.M. (2003) CICBS: Cities' Intellectual Capital Benchmarking System. Methodology and a Framework for Measuring and Managing Intellectual Capital of Cities. A Practical Application in the City of Mataró [online] http://www.intellectualcapitalmanagementsystems.com (accessed 1 February 2012).

World Commission on Environment and Development (1987) Our Common Future, Oxford University Press, Oxford, [online] http:/www.worldinbalance.net/pdf/1987brundtland.pdf (accessed 14 April 2012).

Yigitcanlar, T. (2008) Knowledge-Based Development of Creative Urban Regions, Knowledge International Week, Ibero-American Community for Knowledge Systems, Manizales.

Yigitcanlar, T. (2009) 'Planning for knowledge-based development: global perspectives', Journal of Knowledge Management, Vol. 13, No. 5, pp.228-242.

Yigitcanlar, T. and Velibeyoglu, K. (2008) 'Knowledge-based strategic planning', 3rd International Forum on Knowledge Asset Dynamics, pp.296-306, Matera.

Yigitcanlar, T., Velibeyoglu, K. and Baum, S. (Eds.) (2008) Knowledge-Based Urban Development: Planning and Applications in the Information Era, IGI Global, Hershey, PA. 